\title{
Relações de gênero e iniciação sexual de mulheres adolescentes
}

\author{
GENDER RELATIONS AND SEXUAL INITIATION AMONG ADOLESCENT WOMEN
}

RELACIONES DE GENERO E INICIACIÓN SEXUAL DE MUJERES ADOLESCENTES

\section{Ana Luiza Vilela Borges'}

\section{RESUMO}

Trata-se de estudo transversal conduzido com 222 adolescentes mulheres, entre 15 e 19 anos de idade, moradoras da área de uma unidade de saúde da família na zona leste da cidade de São Paulo, cujo objetivo foi descrever as motivações para iniciar ou não a vida sexual e os fatores associados a tal evento. As adolescentes que já haviam iniciado a vida sexual eram mais velhas, não coabitavam com os pais, estavam ausentes do sistema educacional, habitavam domicílios ocupados e namoravam em maior proporção do que as sem experiência sexual. Observou-se também que, na opinião das entrevistadas, a iniciação sexual, independente do matrimônio, pareceu ser aceita, mas foi largamente relatado o desejo da existência de vínculo afetivo-amoroso com o parceiro da primeira prática sexual, reforçando que o tradicional papel atribuído à sexualidade feminina, pelas relações de gênero, ainda forma a base do comportamento sexual dessas garotas.

\section{DESCRITORES}

Saúde do adolescente. Saúde sexual e reprodutiva. Gênero e saúde.

\section{ABSTRACT}

This is a cross-sectional study conducted with 22215 to 19 year-old female adolescents who lived in the area of a family health unit in the East part of the city of São Paulo. The aim was to describe their motivation for starting sexual life or remaining virgin, as well as the associated factors to the onset of sexual life. The girls that had already initiated their sexual life were older, did not cohabitate with both parents, were out of school, lived in illegally-occupied houses and were dating in a higher proportion than the virgin ones. It was also observed a decrease in the value of virginity, but the first intercourse independently of marriage seemed to be acceptable only when there was a romantic relationship with the partner, showing that traditional gender relations continue to be the basis for those girls' sexual behavior.

\section{KEY WORDS}

Adolescent health.

Sexual and reproductive health. Gender and health.

\section{RESUMEN}

Se trata de un estudio transversal conducido con 222 adolescentes mujeres, entre 15 e 19 años de edad, moradoras del área de una unidad de salud de la familia en la zona leste de la ciudad de São Paulo, cuyo objetivo fue describir las motivaciones para iniciar o no la vida sexual y los factores asociados a tal evento. Las adolescentes que ya habían iniciado la vida sexual eran mayores, no cohabitaban con los padres, estaban ausentes del sistema educacional, habitaban domicilios ocupados y enamoraban en mayor proporción de lo que las sin experiencia sexual. Se observó también que, en la opinión de las entrevistadas, la iniciación sexual, independiente del matrimonio, pareció ser acepta, pero fue largamente relatado el deseo de la existencia del vínculo afectivo-amoroso con la pareja de la primera práctica sexual, reforzando que el tradicional papel atribuido a la sexualidad femenina, por las relaciones de genero, aún forma la base del comportamiento sexual de esas chicas.

\section{DESCRIPTORES}

Salud del adolescente.

Salud sexual y reproductiva.

Género y salud.
I Enfermeira. Professora Doutora do Departamento de Enfermagem em Saúde Coletiva da Escola de Enfermagem, Universidade de São Paulo (EEUSP), São Paulo, SP, Brasil. alvilela@usp.br 


\section{INTRODUÇÃO}

Homens e mulheres têm iniciado sua vida sexual cada vez mais cedo. Diversos estudos brasileiros têm revelado uma tendência de antecipação do início da vida sexual, principalmente entre as mulheres, por meio da observação da diminuição da idade em que ocorre a primeira relação sexual $^{(1-2)}$. Como exemplo, tem-se o estudo realizado pelo Ministério da Saúde ${ }^{(3)}$ em que o valor mediano do início da vida sexual, em 1984, foi 16,0 anos entre as mulheres de 16 a 19 anos de idade. Já em 1998, a idade mediana verificada diminuiu para 15,0 anos. Ainda, a proporção de adolescentes do sexo masculino que tiveram a primeira relação sexual até os 14 anos de idade foi 35,2\% em 1984, ao passo que em 1998 esse percentual subiu para 46,7\%. A proporção de mulheres que tiveram a primeira relação sexual antes dos 14 anos praticamente dobrou entre 1984 e 1998 (13,6\% e 32,3\% respectivamente), ou seja, as mulheres começam a vida sexual mais tardiamente se comparadas aos homens, porém a mudança ocorrida na proporção de iniciação sexual de 1984 a 1998 é muito superior à observada entre eles.

Ressalte-se que, na maioria das vezes, a iniciação sexual de adolescentes do sexo masculino ocorre mais precocemente do que a de adolescentes do sexo feminino ${ }^{(1,3-5)}$. Tais diferenças na idade de iniciação sexual de homens e mulheres são bem descritas por estudos populacionais que analisam seus dados por meio da variável sexo. Todavia, são os estudos que tomam como categoria de análise as relações de gênero que mais apreendem a diversidade e a complexidade das trajetórias sexuais de homens e mulheres. Assumir a perspectiva de gênero como referencial teórico implica não naturalizar as diferenças entre os sexos, mas considerá-las como conseqüência de uma construção social e cultural dos significados do que é ser homem e o que é ser mulher, hierarquias e relações de poder em cada tempo, espaço e grupo social.

Um dos pressupostos da categoria gênero é a rejeição ao determinismo biológico que evoca a diferença sexual. Além disso, propõe-se a entender tal diferença como uma organização social da relação entre os sexos e enfatiza a forma como os discursos sociais e culturais construíram os chamados papéis sociais em diferentes sociedades e períodos históricos.

Gênero pode ser entendido como o processo pelo qual a sociedade classifica e atribui valores e normas, construindo assim, as diferenças e hierarquias sexuais, delimitando o que seriam papéis masculinos e femininos. Dessa forma, a interpretação acerca da diferença entre os sexos

pode apontar para uma relação de complementaridade ou de hierarquia, a depender da cultura, tendo como modelo uma relação de dois pólos, na qual quaisquer que sejam as características atribuídas a um dos pólos, estas estarão em oposição às características atribuídas ao outro(6).
Pode-se concluir que as concepções de feminilidade situam as mulheres em esferas opostas àquelas em que se encontram os homens, ou seja, a construção dos papéis sociais tem como um dos elementos norteadores que certas atividades e atitudes são inerentemente masculinas ou femininas ${ }^{(7)}$, podendo direcionar homens e mulheres a adotar determinados comportamentos em função daquilo que é esperado no grupo sociocultural em que se reproduzem, social e biologicamente.

Cabe salientar que as questões de gênero têm se mostrado fundamentais na condução das escolhas reprodutivas de adolescentes, particularmente o momento da primeira relação sexual. As explicações acerca das diferenças no início da vida sexual entre homens e mulheres baseiam-se no fato de que as normas e expectativas sociais em relação à idade $\mathrm{e}$ às circunstâncias adequadas para as primeiras práticas sexuais variam conforme o sexo ${ }^{(8)}$.

No intuito de enfatizar as diferentes motivações para o desencadeamento de práticas sexuais entre homens e mulheres, uma pesquisadora afirmou que:

\begin{abstract}
circula unânime entre as mulheres o sentimento de entrega em relação ao ato sexual, dando caráter valorativo de raro à virgindade. Ao mesmo tempo em que existe o desejo de se descobrir, impõe-se a necessidade de se preservar. A experiência masculina, em contrapartida, traduz-se em duas atitudes: numa, o desempenho sexual é visto como um ganho, sustentando o poder da masculinidade, noutra, a atitude é decididamente romântica, em que o homem busca entregar-se no momento certo e à parceira certa(9).
\end{abstract}

Essa autora chamou a atenção para uma fase de transição em relação a antigos valores a respeito da iniciação sexual, revestida de contradições: a perda está conjugada a um ganho (perde-se a virgindade, porém ganha-se maturidade e amor do parceiro) e os valores tradicionais estão conjugados aos modernos (os homens devem demonstrar uma disposição ativa para o sexo, porém muitos já passam também a relacionar a experiência sexual ao amor).

Em concordância com a compreensão de que a iniciação sexual não está desvencilhada do ideal romântico entre as mulheres, um estudo antropológico ${ }^{(10)}$ desenvolvido com um grupo de estudantes de 13 a 18 anos de camadas populares em Belém do Pará/PA, descreveu que, no depoimento das garotas entrevistadas,

a primeira experiência sexual aparece como formulada em termos de uma entrega, cuja legitimidade ocorre no âmbito de uma relação afetiva já consolidada (o namoro), concretizada a partir da apresentação do parceiro à família, seguida do pedido em namoro ${ }^{(10)}$.

Esses estudos evidenciaram que valores diferenciados social, histórica e culturalmente construídos - são atribuídos à primeira relação sexual e norteiam um início da vida sexual distinto entre homens e mulheres que, por sua vez, 
têm um papel preponderante para a manutenção de tais valores no grupo em que vivem.

Dessa forma, este trabalho toma como pressuposto que as motivações diferenciadas para o engajamento na vida sexual de homens e mulheres são fruto da construção de suas identidades masculinas e femininas baseadas nas relações de gênero. Partindo de um olhar sobre a saúde sexual e reprodutiva de mulheres adolescentes, o estudo justifica-se no sentido que as relações de gênero têm impacto profundo nas escolhas contraceptivas tendo em vista que as mulheres tendem a não usar ou a abandonar o uso de preservativos masculinos em relacionamentos com parceiros estáveis quando há envolvimento afetivo-amoroso, tornando-se mais vulneráveis às doenças sexualmente transmissíveis (dst) e aids ${ }^{(11-12)}$.

Este estudo pretende, assim, caracterizar as motivações que cercam as escolhas acerca da iniciação sexual de mulheres adolescentes e identificar os aspectos que estejam associados à sua iniciação sexual.

\section{MÉTODO}

Trata-se de estudo transversal desenvolvido em uma amostra representativa dos adolescentes de 15 a 19 anos de idade de ambos os sexos, moradores da área adscrita de uma unidade de saúde da família da zona leste do Município de São Paulo/SP. A escolha de dessa faixa etária justificou-se por compreender o período da adolescência em que a iniciação sexual ocorre com maior freqüência, mas ainda permite comparações, pois nesse período podem ser encontradas proporções razoáveis de indivíduos que ainda não tiveram relações sexuais.

Os sujeitos entrevistados foram selecionados por amostragem sistemática, com base em uma listagem obtida por meio do Sistema de Informação da Atenção Básica (SIAB) e ordenada por micro-área e pelo número das famílias cadastradas no Programa de Saúde da Família que tinham ao menos um adolescente entre 15 e 19 anos de idade.

O tamanho amostral foi calculado baseando-se na precisão desejada para se estimar a porcentagem de adolescentes de 15 a 19 que já tivessem iniciado a vida sexual. Tal proporção foi considerada igual a $60 \%{ }^{(3)}$, com erro máximo em valor absoluto de 5\% e com nível de confiança de $95 \%$. Para se obter a estimativa final do tamanho da amostra, esse valor foi ajustado usando-se um fator de correção para população finita. Ainda, considerando a possibilidade de perdas, foram acrescidos $30 \%$ para que não houvesse redução do tamanho da amostra.
Foram entrevistados 406 adolescentes entre 15 e 19 anos de idade, por meio de um formulário estruturado e précodificado, entre junho e dezembro de 2002. As entrevistas foram realizadas, majoritariamente, no próprio domicílio dos adolescentes selecionados. É preciso salientar que a entrevista foi conduzida respeitando-se a privacidade do jovem e, mesmo tendo sido planejada para ser conduzida no domicílio do adolescente, foi dada a opção para que ele escolhesse o local em que se sentisse mais confortável para responder às perguntas como, por exemplo, um cômodo específico da casa, quintal, casa de vizinhos ou parentes, espaço público, centro de juventude e outros. Além disso, foram oferecidos aos entrevistados preservativos masculinos, panfletos educativos sobre prevenção de dst e aids e uma listagem com os serviços disponíveis na cidade de São Paulo para mulheres vítimas de violência.

A análise dos dados foi realizada por meio do software Statistical Package for Social Sciences 11.0 (SPSS). Os dados foram descritos por meio de proporções e número absoluto. A análise das variáveis associadas à iniciação sexual foi realizada por meio do teste de associação pelo Qui-quadrado e a comparação entre as idades médias foi realizada por meio do teste Mann-Whitney.

Este estudo adotou procedimentos que garantiram a não-discriminação ou estigmatização dos indivíduos envolvidos na pesquisa. As jovens foram convidadas a participar do estudo após uma explicação de seus objetivos, do conteúdo de suas questões e da instituição em que era desenvolvido. Foi enfatizado que as perguntas eram de cunho íntimo e que elas poderiam recusar a continuidade da entrevista a qualquer momento. Também foi assegurado que sua identidade seria mantida em sigilo. Foram garantidos a privacidade, confidencialidade e anonimato e respeitados os valores socioculturais. Os consentimentos foram obtidos com os responsáveis pela adolescente ou com ela própria, desde que com idade igual ou superior a 18 anos. Esta pesquisa foi aprovada pela Comissão de Ética e Pesquisa da Faculdade de Saúde Pública da Universidade de São Paulo (Processo CEP n. 238/01).

Entre os entrevistados, $222(54,7 \%)$ eram do sexo feminino e $184(45,3 \%)$ do sexo masculino. Por conta dos objetivos do presente estudo, os dados apresentados são concernentes apenas às 222 mulheres entrevistadas. Os dados relativos aos adolescentes homens serão apresentados em outras publicações.

A apresentação dos resultados foi dividida em três partes: 
a) dados de todas as adolescentes segundo as variáveis sociodemográficas (idade, cor, estudo atual, trabalho atual, tipo de moradia, coabitação) e relacionais (amigos virgens e namoro atual) comparadas entre as que já haviam iniciado a vida sexual e aquelas que não haviam. Durante as entrevistas, a primeira relação sexual, aqui também denominada de iniciação sexual, foi enfatizada como sendo sexo com penetração vaginal ou anal.

b) dados das adolescentes que já tiveram alguma relação sexual segundo a variável razão para o engajamento na vida sexual. A pergunta permitia apenas uma resposta e era estimulada por meio das alternativas curiosidade, atração, amor, pressão do parceiro e queria perder a virgindade. As alternativas pressão dos amigos e outra razão não foram referidas por nenhuma adolescente.

c) dados das adolescentes que nunca tiveram uma relação sexual segundo a variável razão para o não engajamento em atividade sexual. As alternativas préestabelecidas foram ainda não encontrou a pessoa certa, quer se casar virgem, não teve oportunidade, tem medo de engravidar e tem medo de dst e aids - as duas últimas agrupadas em uma só - além de ainda é muito nova. Nenhuma adolescente relatou outra razão. Outra variável analisada foi o momento considerado mais adequado para ter a primeira relação sexual, cujas alternativas pré-estabelecidas foram quando se casar, quando for noiva, quando tiver namorado - as duas últimas agrupadas em uma só - assim que possível, quando for mais madura, quando gostar de alguém. As alternativas quando tiver determinada idade e quando terminar os estudos não foram apontadas por nenhuma adolescente. Cabe ressaltar que nenhuma adolescente recusou-se a responder essas questões e nem apontaram a alternativa não sei.

\section{CARACTERIZAÇÃO DAS ENTREVISTADAS}

O projeto foi aprovado pelo Conselho de Ética e Pesquisa da Faculdade de Saúde Pública da USP (n. 238/01), em novembro de 2001.

A caracterização das mulheres adolescentes revela que tinham 16,8 anos de idade em média $(\mathrm{dp}=1,4)$ e mediana de 17,0 anos. A maior parte era estudante (73,9\% ou 164). Entre essas, $10,0 \%$ (22) também estavam trabalhando. A ausência de inserção escolar simultaneamente à ausência de inserção no mercado de trabalho atingiu 46 adolescentes $(20,7 \%)$. Muitas moravam em casas próprias $(66,2 \%)$ ou de aluguel $(8,6 \%)$, porém $25,2 \%$ relataram morar em habitações ocupadas. Seus domicílios possuíam em média 5,1 cômodos $(\mathrm{dp}=2,1)$ e 4,2 moradores. As adolescentes classificaram-se como de cor parda $(40,5 \%)$ e preta $(15,8 \%)$, ao passo que 43,2\% referiram ser de cor branca. Apenas uma adolescente relatou ser da cor amarela e nenhuma referiu ser indígena.

A maioria das adolescentes nasceu na Região Metropolitana de São Paulo (85,1\%), apesar de uma considerável proporção de seus pais e mães $(67,3 \%$ e $82,6 \%$ respectivamente) ter nascido em outras regiões do país, principalmente o Nordeste, e migrado para a cidade de São Paulo. Em relação ao estado conjugal, 91,4\% (180) das adolescentes disseram ser solteiras, 17 estavam unidas e duas encontravam-se separadas no momento da entrevista. A caracterização revelou, pois, que eram mulheres inseridas em contextos de precária inserção social, com perfil típico de jovens moradoras de áreas periféricas de grandes cidades brasileiras.

\section{RESULTADOS}

A maior idade, a falta de inserção escolar, a habitação do tipo invadida, a coabitação com apenas um dos pais e estar namorando foram associados estatisticamente ao início da vida sexual, resultados mostrados na Tabela 1. As adolescentes virgens eram um ano mais novas que as sexualmente experientes $(16,4 \pm 1,3$ e 17,4 1 1,2 anos, respectivamente).

As adolescentes que já haviam iniciado a vida sexual referiram, em maior parte, o amor pelo primeiro parceiro sexual como a principal motivação para iniciação sexual (52,5\%), conforme Figura 1.

Ao todo, 121 adolescentes não haviam tido nenhuma relação sexual. Um pouco menos da metade revelou que ainda não havia encontrado a pessoa certa para a iniciação sexual $(43,8 \%)$ e, por isto, permanecia virgem. Praticamente um quarto justificou sua opção porque se considerava muito nova para ter relação sexual e outro quarto porque queria se casar virgem. Outras razões relatadas são mostradas na Figura 2.

Cabe enfatizar que não houve diferença estatisticamente significativa nas idades médias entre as adolescentes no tocante a suas razões para o não engajamento sexual ou à sua opinião sobre o momento mais adequado para a ocorrência desse evento. 
Tabela 1 - Fatores associados à iniciação sexual de mulheres adolescentes - São Paulo - 2002

\begin{tabular}{|c|c|c|c|c|c|c|c|}
\hline \multirow[t]{3}{*}{ Variável } & \multicolumn{4}{|c|}{ Iniciou a vida sexual } & \multicolumn{2}{|c|}{ Total } & \multirow[t]{3}{*}{$\mathrm{p}^{*}$} \\
\hline & \multicolumn{2}{|c|}{ Não } & \multicolumn{2}{|c|}{ Sim } & \multirow[b]{2}{*}{$\mathrm{N}$} & \multirow[b]{2}{*}{$\%$} & \\
\hline & $\mathrm{N}$ & $\%$ & $\mathrm{~N}$ & $\%$ & & & \\
\hline \multicolumn{8}{|l|}{ Idade } \\
\hline 15 & 40 & 33,1 & 6 & 5,9 & 46 & 20,7 & \multirow[t]{5}{*}{$<0,0001$} \\
\hline 16 & 38 & 31,4 & 17 & 16,8 & 55 & 24,8 & \\
\hline 17 & 16 & 13,2 & 31 & 30,7 & 47 & 21,2 & \\
\hline 18 & 15 & 12,4 & 24 & 23,8 & 39 & 17,6 & \\
\hline 19 & 12 & 9,9 & 23 & 22,8 & 35 & 15,8 & \\
\hline \multicolumn{8}{|l|}{ Cor* } \\
\hline Branca & 57 & 47,1 & 39 & 38,6 & 96 & 43,2 & \multirow[t]{2}{*}{0,0720} \\
\hline Parda/preta & 64 & 52,9 & 61 & 60,4 & 125 & 56,3 & \\
\hline \multicolumn{8}{|l|}{ Estudo atual } \\
\hline Não & 15 & 12,4 & 43 & 42,6 & 58 & 26,1 & \multirow[t]{2}{*}{$<0,0001$} \\
\hline Sim & 106 & 87,6 & 58 & 57,4 & 164 & 73,9 & \\
\hline \multicolumn{8}{|l|}{ Trabalho atual } \\
\hline Não & 104 & 86,0 & 84 & 83,2 & 188 & 84,7 & \multirow[t]{2}{*}{0,5670} \\
\hline Sim & 17 & 14,0 & 17 & 16,8 & 34 & 15,3 & \\
\hline \multicolumn{8}{|l|}{ Tipo de moradia } \\
\hline Própria/alugada & 99 & 81,8 & 67 & 66,3 & 166 & 74,8 & \multirow[t]{2}{*}{0,0082} \\
\hline Invadida & 22 & 18,2 & 34 & 33,7 & 56 & 25,2 & \\
\hline \multicolumn{8}{|c|}{ Mora com ambos os pais } \\
\hline Sim & 83 & 68,6 & 43 & 42,6 & 126 & 56,8 & \multirow[t]{2}{*}{$<0,0001$} \\
\hline Não & 38 & 31,4 & 58 & 57,4 & 96 & 46,2 & \\
\hline \multicolumn{8}{|c|}{ Maior parte dos amigos } \\
\hline É virgem & 50 & 41,3 & 32 & 31,7 & 82 & 36,9 & \multirow[t]{2}{*}{0,1383} \\
\hline Não é virgem & 71 & 58,7 & 69 & 68,3 & 140 & 63,1 & \\
\hline \multicolumn{8}{|l|}{ Namoro atual ${ }^{* *}$} \\
\hline Não & 95 & 78,5 & 29 & 34,5 & 124 & 60,5 & \multirow[t]{2}{*}{$<0,0001$} \\
\hline Sim & 26 & 21,5 & 55 & 65,5 & 81 & 39,5 & \\
\hline Total & 121 & 100,0 & 101 & 100,0 & 222 & 100,0 & \\
\hline
\end{tabular}

* Excluída 1 adolescente que se classificou como amarela.

**Excluídas 17 mulheres unidas.

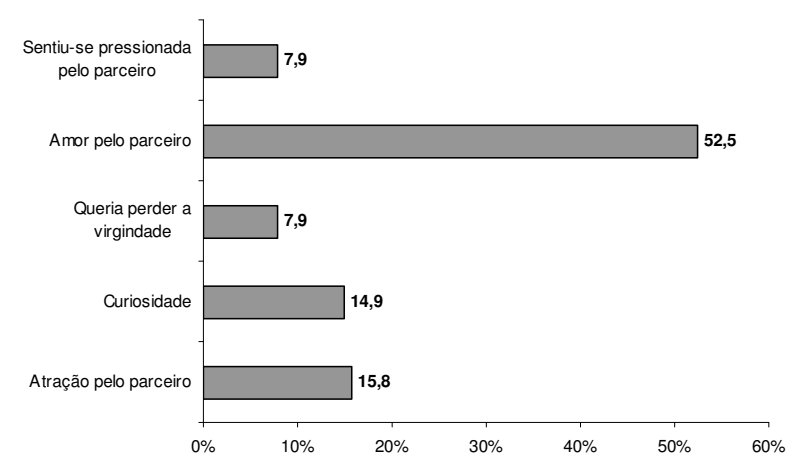

Figura 1 - Razões de iniciação sexual segundo adolescentes com experiência sexual - São Paulo - 2002

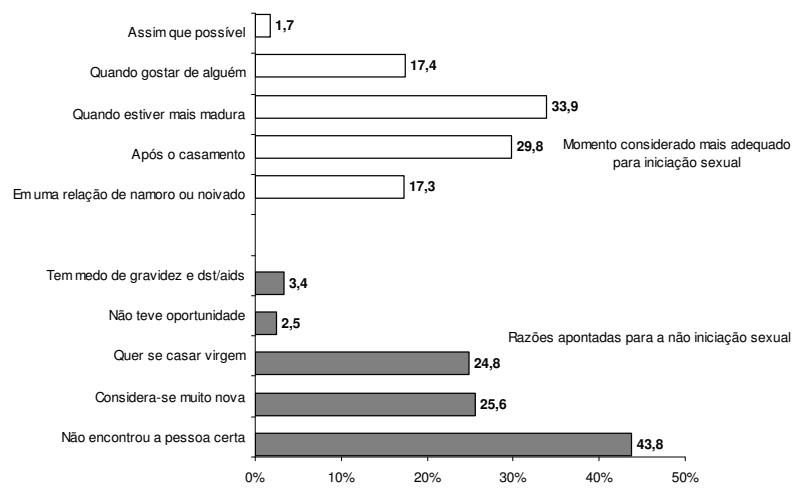

Figura 2 - Distribuição das adolescentes sem experiência sexual segundo as razões apontadas para não ter iniciado a vida sexual e o momento considerado mais adequado para a iniciação sexual - São Paulo - 2002 


\section{DISCUSSÃO}

A iniciação sexual é um evento que ocorre com maior freqüência na adolescência, no entanto, os dados mostraram que o maior salto na proporção de mulheres que haviam iniciado sua vida sexual ocorreu a partir dos 16 anos de idade. Já foi descrito ${ }^{(11)}$ que as experiências pré-sexuais, como o primeiro beijo e o ficar, ocorrem antes dos 14 anos de idade e que a primeira relação sexual tende a se dar após os 15 anos de idade. Isso parece mostrar que a entrada na vida sexual ativa das mulheres adolescentes é um processo gradual - ou seja, há uma fase de experimentação física, relacional e pessoal, assim como de impregnação de uma certa cultura sexual do grupo social a que a adolescente pertence ${ }^{(12)}$ - que se inicia logo nos primeiros anos da adolescência, mas culmina com a relação sexual propriamente dita nos anos mais próximos do fim da adolescência, se adotada a faixa etária de 10 a 19 anos de idade como a etapa cronológica que a Organização Mundial da Saúde compreende como sendo adolescência.

Dessa forma, não causa surpresa que a idade tenha se mostrado associada ao início da vida sexual, mas esse dado chama a atenção para a necessidade de se estabelecer ações de promoção da saúde sexual que alcancem as mulheres adolescentes antes que tenham tido práticas sexuais que tragam algum tipo de vulnerabilidade às dst, aids e gestações não planejadas, e não apenas quando procuram a unidade básica de saúde por conta de suspeita de gravidez, para a realização do pré-natal ou da prevenção do câncer de colo de útero.

Além disso, a maior proporção de adolescentes que já haviam iniciado a vida sexual ter sido observada justamente entre aquelas que se encontravam ausentes do sistema escolar e que habitavam domicílios invadidos revela que esse evento é também socialmente determinado. Tais resultados estão em acordo com o Ministério da Saúde ${ }^{(3)}$, que encontrou maior precocidade de iniciação sexual entre o segmento de menor escolaridade e entre o segmento negro - não restrito ao grupo étnico, mas ao grupo socialmente mais desfavorecido (ao contrário dos resultados deste estudo, em que a cor obteve um valor de $p$ baixo, mas não estatisticamente significativo) - e com outro estudo ${ }^{(12)}$ que enfatizou que a experiência sexual está articulada com as condições sociais, visto que os resultados de sua pesquisa realizada com uma amostra representativa de mulheres jovens de três capitais brasileiras revelaram que o nível de instrução materna e o nível de renda familiar têm forte impacto na idade de iniciação sexual, ou seja, as mulheres de grupos sociais mais empobrecidos iniciam a vida sexual mais cedo.

O fato de mulheres provenientes de camadas sociais mais baixas iniciarem sua vida sexual mais cedo pode ocasionar um impacto em sua saúde reprodutiva e sexual, tendo em vista sua diminuída capacidade de negociação do uso de preservativos masculinos ${ }^{(5,11)}$ e também do mais baixo nível de conhecimento acerca dos métodos contraceptivos, pois esse conhecimento entre mulheres tende a aumentar com a idade $^{(13)}$.

Por outro lado, o relato de que a maior parte dos amigos já havia iniciado a vida sexual não foi estatisticamente diferente entre as adolescentes virgens e não virgens. Vários estudos têm enfatizado a influência que os pares exercem no comportamento sexual de adolescentes. Tais influências têm sido descritas como um fator associado, não apenas à iniciação sexual, mas a vários outros comportamentos reprodutivos, entre eles o uso de contraceptivos e, mais especificamente, o uso de preservativos masculinos ${ }^{(14-15)}$. A influência dos pares pôde ser identificada por meio do relato de adolescentes que se sentiram pressionados pelos amigos a iniciar a vida sexual ${ }^{(15)}$, sendo que os homens pareceram ser mais propensos a se submeter a essa pressão do que as mulheres ${ }^{(14)}$.

Foi relatado ${ }^{(15)}$ que os adolescentes com experiência sexual achavam que a maioria de seus amigos também já era experiente sexualmente, em uma proporção muito maior do que os adolescentes que ainda eram virgens, independentemente do sexo. E os autores afirmaram que quando adolescentes mais novos percebem que a maior parte de seus pares tem vida sexual, eles passam a demonstrar a intenção de também iniciar a vida sexual e, conseqüentemente, concretizam esse desejo.

Esses estudos confirmam que a iniciação sexual pode ser estimulada, entre outros, em razão da difusão de um modelo de comportamento sexual ditado pelos pares que, por sua vez, também estão sujeitos às normas sociais estabelecidas para modelar as condutas sexuais, não estando as mulheres excluídas desse processo. A influência dos pares parece ser moldada pelo próprio significado atribuído culturalmente à sexualidade, no qual aos homens cabe o papel de não resistir ao impulso sexual, e às mulheres cabe o papel de controlar seus impulsos, ou ao menos, cedê-los apenas às pessoas com as quais têm vínculos afetivo-amorosos, ratificando as relações de gênero presentes no cenário da iniciação sexual.

No entanto, neste estudo, morar com apenas um dos pais foi estatisticamente associado à iniciação sexual entre as entrevistadas, denotando um possível maior controle parental entre aquelas garotas que moravam com ambos os pais. Parece que o tradicional papel que cabe à mulher no tocante à sua experimentação sexual pode ter sido mais enfatizado e considerado quando advinda do grupo parental do que do grupo de pares, provavelmente por conta do modo de socialização familiar, nas conversas entre mãe e filha sobre sexo e na divisão sexual das tarefas domésticas, além do controle parental sobre o namoro e lazer das filhas ${ }^{(9)}$.

No que diz respeito às motivações para a iniciação sexual, os resultados mostraram o relato das adolescentes que 
iniciaram a vida sexual por terem sido pressionadas, evidenciando possíveis contextos de coerção e violência. Todavia, o que mais chamou a atenção foi o fato que várias adolescentes revelaram que tiveram a primeira relação sexual por conta de curiosidade, atração pelo parceiro e porque sentiam a necessidade de perder a virgindade, desvinculando sexo do sentimento de amor. Tais relatos sugerem também que possa haver, muito possivelmente, um código de conduta prescrevendo que, em determinado momento ou a partir de uma certa idade, a virgindade passa a ser um peso na vida dessas adolescentes (tal como tem ocorrido entre os homens há tempos) servindo também como elemento de pressão para que haja a iniciação sexual.

Ou seja, algumas adolescentes iniciaram a vida sexual claramente porque se sentiram pressionadas pelos seus parceiros, mas outra parte considerável pode ter iniciado sua vida sexual sob uma outra forma de pressão, tão sutil e inquestionável que não foi e não é usualmente identificável, significando que a desvalorização da virgindade feminina nesse grupo é parte do repertório que incide nas escolhas acerca da iniciação sexual.

O namoro foi também associado ao início da vida sexual. Desse modo, a maior parte das adolescentes com experiência sexual estava namorando no momento da entrevista, ao contrário da maior parte das garotas virgens. O namoro já foi descrito como o tipo de relacionamento, juntamente com o ficar, em que os caminhos são abertos para uma mútua exploração sexual - muito antes da primeira relação sexual, a maior parte dos adolescentes já se engajou em experiências ditas pré-sexuais, como carícias e toques mais íntimos ${ }^{(16)}$, levando ao aprofundamento da intimidade até a opção pela relação sexual.

É possível, pois, considerar que o namoro necessitaria estar entre os tópicos abordados nas intervenções realizadas com os adolescentes na atenção básica justamente por constituir um espaço de exercício das relações entre homens e mulheres que, sejam mais igualitárias ou mais hierarquizadas, poderão ser transpostas às atitudes e práticas sexuais e contraceptivas.

O relacionamento sexual iniciado em uma relação de namoro tem um significado especial entre as mulheres, pois há a possibilidade de conjugar a iniciação sexual com amor ou paixão; a isso, soma-se a preocupação feminina em se preservar no espaço público. Esses dois aspectos orientam os critérios de escolha do namorado enquanto parceria preferencial de iniciação sexual ${ }^{(9)}$.

Um pouco mais da metade das adolescentes indicou ter iniciado sua vida sexual por amor ao parceiro $(52,5 \%)$. Para essas mulheres, o amor e o sexo seriam experiências que correspondem a espaços muito próximos entre si. Mesmo que tais mulheres tenham rompido a barreira de se preservarem virgens até o matrimônio, pode-se destacar que a inicia- ção sexual só foi possível porque havia romance e envolvimento afetivo-amoroso com o primeiro parceiro. Parece que

o enfraquecimento do modelo tradicional de virgindade não levou a uma transformação total. A decisão de preservar (ou não) a virgindade é cada vez mais efeito de uma estratégia feminina e de um cálculo decorrente de uma regra de prudência, mais do que de respeito por um valor social ou moral. Preservar a virgindade é preservar o futuro(17).

Em relação às adolescentes que nunca haviam tido qualquer relação sexual $(54,5 \%)$, saliente-se que a maior parte justificou sua opção pela virgindade por conta de razões de ordem amorosa, como o fato de não ter encontrado a pessoa certa ou porque queria se manter virgem até o casamento, totalizando $66,4 \%$. A ênfase no aspecto afetivo-amoroso na iniciação sexual atribuída pelas mulheres virgens foi ratificada pelas suas respostas no tocante ao momento considerado mais adequado para a sua iniciação sexual. O caráter romântico emergiu mais uma vez, tendo em vista que $64,5 \%$ das entrevistadas relataram um contexto de relacionamento com envolvimento de sentimentos de paixão e amor como ideal para iniciar-se sexualmente, tendo como pano de fundo o namoro, o noivado, o casamento ou o momento em que gostasse de alguém. Praticamente uma em cada quatro adolescentes sem experiência sexual elegeu o casamento como o contexto ideal da iniciação sexual. Entre as mulheres, já foi descrito que

\section{as representações sobre o lugar do amor nos relaciona- mentos sexuais são unânimes: é imprescindível. É como se o amor validasse o sexo ${ }^{(18)}$.}

Outro ponto a ser destacado é o valor que a iniciação sexual tem como passagem para a vida adulta para estas adolescentes. A necessidade de esperar ser mais madura para ter a primeira relação sexual foi referida por 33,9\% das mulheres virgens. Relatos descritos em pesquisas que usaram entrevistas em profundidade denotam que, para as adolescentes, a iniciação sexual as coloca como autoras de seus atos, exigindo atitudes responsáveis, tomadas de decisão e conseqüentemente responsabilização pelos seus atos, inserindo-as definitivamente em um universo de maior maturidade ${ }^{(9,18)}$.

Cabe enfatizar que uma comparação entre os argumentos das adolescentes com e sem experiência sexual faz emanar um certo consenso entre ambos, uma vez que, de forma geral, é permitida a iniciação sexual independentemente do matrimônio, mas que seja permeada por relacionamentos em que vigoram compromissos e laços afetivos, o que concorda com a idéia de que os arranjos de amor e sexo

apresentam uma coexistência do tradicional e do moderno, regendo as relações de gênero e conformando os múltiplos processos de individuação(9).

Pode-se dizer, então, que a perda da virgindade não está totalmente banalizada, já que o arrefecimento do valor social 
à virgindade não diminui a importância que as mulheres lhe dão nem a atenção que os homens lhe dedicam, ainda que exista uma outra visão acerca da virgindade na qual ela é fortemente desvalorizada, como um fardo do qual é preciso se livrar ${ }^{(17)}$. Mesmo que as mulheres estejam iniciando sua vida sexual cada vez mais cedo e que seu calendário de iniciação sexual esteja próximo ao dos homens ${ }^{(11)}$, suas motivações para o engajamento sexual continuam, em certa medida, respondendo aos papéis tradicionalmente atribuídos à mulher, qual sejam o amor, romance e compromisso como propulsores das primeiras práticas sexuais.

\section{CONCLUSÃO}

A partir da análise dos resultados apresentados e das leituras dos estudos referenciados, parece claro que o comportamento sexual de mulheres adolescentes vem se modificando, não apenas por conta da maior precocidade na idade de iniciação sexual, mas também nas escolhas do

\section{REFERÊNCIAS}

1. BEMFAM - Bem-Estar Familiar no Brasil. Pesquisa Nacional sobre Demografia e Saúde - 1996. Rio de Janeiro; 1997.

2. Melo AV, Yazaki LM. O despertar do desejo. In: São Paulo (Estado). Secretaria de Economia e Planejamento. Fundação Sistema Estadual de Análise de Dados (SEADE). 20 anos no ano 2000: estudos sociodemográficos sobre a juventude paulista. São Paulo; 1998. p. 119-25.

3. Brasil. Ministério da Saúde. Coordenação Nacional DST/AIDS. Centro Brasileiro de Análise e Planejamento (CEBRAP). Pesquisa sobre comportamento sexual da população brasileira e percepções sobre HIV/AIDS. Brasília: Ministério da Saúde; 2000.

4. Pirotta KCM. Não há guarda-chuva contra o amor: estudo do comportamento reprodutivo e de seu universo simbólico entre jovens universitários da USP [tese]. São Paulo: Faculdade de Saúde Pública, Universidade de São Paulo; 2002.

5. Aquino EML, Heilborn ML, Knauth D, Bozon M, Almeida MC, Araújo J, et al. Adolescência e reprodução no Brasil: a heterogeneidade dos perfis sociais. Cad Saúde Pública. 2003;19 Supl 2:377-88.

6. Villela WV, Arilha M. Sexualidade, gênero e direitos sexuais e reprodutivos. In: Berquó E, organizadora. Sexo e vida: panorama da saúde reprodutiva no Brasil. Campinas: Ed. UNICAMP; 2003. p. $95-150$

7. Fonseca RMGS. Eqüidade de gênero e saúde das mulheres. Rev Esc Enferm USP. 2005;39(4):450-9.

8. Heilborn ML. A primeira vez nunca se esquece. Rev Estud Fem. 1998;6(2):394-405.

9. Rieth F. Ficar e namorar. In: Bruschini C, Hollanda HB, editoras. Horizontes plurais: novos estudos de gênero no Brasil. São Paulo: 34; 1998. p. 113-33. momento e parcerias mais adequadas para a ocorrência da primeira relação sexual. Contudo, se por um lado há uma aparente mudança no valor atribuído à virgindade feminina, as relações de gênero permanecem configurando de forma intensa a sexualidade feminina, circunscrevendo a iniciação sexual quase estritamente a uma relação de amor e de confiança.

Dessa forma, os profissionais de saúde necessitam estar preparados para a diversidade dos modos de viver a adolescência e de viver a sexualidade na adolescência bem como para o impacto que as decisões que permeiam a iniciação sexual das adolescentes, largamente influenciadas pelas relações de gênero ainda vigentes, podem ocasionar em sua saúde sexual e reprodutiva. Além disso, deve-se ter em vista que a compreensão dos aspectos que cercam o comportamento sexual de mulheres adolescentes possibilita também uma maior compreensão da sua consequiência para os homens, para a vida em parceria e para alcançar uma maior equiidade de gênero.

10. Pantoja ALN. "Ser alguém na vida": uma análise sócio-antropológica da gravidez/ maternidade na adolescência, em Belém do Pará, Brasil. Cad Saúde Pública. 2003;19 Supl 2:335-43.

11. Borges ALV, Schor N. Início da vida sexual na adolescência e relações de gênero: um estudo transversal em São Paulo, Brasil, 2002. Cad Saúde Pública. 2005;21(2):499-507.

12. Heilborn ML, Cabral CS, Bozon M, Grupo GRAVAD. Gênero e carreiras sexuais e reprodutivas de jovens brasileiros. In: Anais do $15^{\circ}$ Encontro Nacional de Estudos Populacionais [texto na Internet]; 2006 set. 18-22 [citado 2006 nov. 20]; Caxambu. Caxambu: ABEP; 2006. Disponível em: http://www.abep. nepo.unicamp.br/encontro2006/docspdf/ABEP2006_607.pdf.

13. Paniz VMV, Fassa AG, Silva MC. Conhecimento sobre anticoncepcionais em uma população de 15 anos ou mais de uma cidade do Sul do Brasil. Cad Saúde Pública. 2005;21(6):1747-60.

14. Wellings K, Nanchahal K, Macdowall W, McManus S, Erens $\mathrm{B}$, Mercer $\mathrm{CH}$, et al. Sexual behaviour in Britain: early heterosexual experience. Lancet. 2001;358(9296):1843-50.

15. Kinsman SB, Romer D, Furstenberg FF, Schwarz DF. Early sexual initiation: the role of peer norms. Pediatrics. 1998;102(5):1185-92.

16. Schwartz IM. Sexual activity prior to coital initiation: a comparison between males and females. Arch Sex Behavior. 1999;28(1):63-9.

17. Bozon M, Heilborn ML. As carícias e as palavras: iniciação sexual no Rio de Janeiro e em Paris. Novos Est CEBRAP. 2001;(59):111-35.

18. Heilborn ML. Sexualidade: o olhar das ciências sociais. Rio de Janeiro: Jorge Zahar; 1999. Construção de si, gênero e sexualidade; p. 40-58. 